\title{
Intramedullary Spinal Cord Metastases in Breast Cancer: Report a Case
}

\author{
Masahiro Kitada*, Nana Takahashi, Shunsuke Yasuda, Satoshi Okazaki, Kei Ishibashi, Satoshi Hayashi \\ Department of Breast Disease Center, Asahikawa Medical University, Asahikawa, Japan \\ Email: *k1111@asahikawa-med.ac.jp,n-takahashi@asahikawa-med.ac.jp, s-yasuda@asahikawa-med.ac.jp, \\ syugoshin.19851221@gmail.com,kei_dod@hotmail.com, shayashi@asahikawa-med.ac.jp
}

How to cite this paper: Kitada, M., Takahashi, N., Yasuda, S., Okazaki, S., Ishibashi, K. and Hayashi, S. (2016) Intramedullary Spinal Cord Metastases in Breast Cancer: Report a Case. Journal of Cancer Therapy, 7, 1034-1038.

http://dx.doi.org/10.4236/jct.2016.713099

Received: November 20, 2016

Accepted: December 17, 2016

Published: December 20, 2016

Copyright $\odot 2016$ by authors and Scientific Research Publishing Inc. This work is licensed under the Creative Commons Attribution International License (CC BY 4.0).

http://creativecommons.org/licenses/by/4.0/

\begin{abstract}
Background: Intramedullary spinal cord metastasis (ISCM) from breast cancer is a relatively rare disease. We present this disease. Case presentation: The patient was a 67-year-old woman with lung metastasis appearing 3 years after breast cancer surgery. Complete remission was achieved for the metastatic lesion with chemotherapy, but multiple cerebellar metastases were found 3 months after the completion of chemotherapy. Whole-brain irradiation was administered, resulting in symptomatic improvement. Approximately 6 months later, the patient experienced weakness in the lower extremities and difficulty walking. Magnetic resonance imaging detected a well-defined intraspinal tumor measuring $13 \times 13 \times 30 \mathrm{~mm}$ at the level of Th12-L1. After 20-Gy irradiation to the tumor, oral steroid administration, and rehabilitation, the patient regained the ability to walk. Eight months have passed, to date, since these interventions and the patient is currently receiving treatment for metastases to bones, including the spine, but is still capable of walking without difficulty. We herein report this case with a review of the relevant literature. Conclusion: ISCM in the breast cancer is relatively rare. But, it is the clinical condition which it should always place in the mind.
\end{abstract}

\section{Keywords}

Breast Cancer, Intramedullary Spinal Cord Metastasis (Iscm), Brain Metastasis

\section{Introduction}

Intramedullary spinal cord metastasis (ISCM) from a malignant tumor is relatively rare, accounting for just $0.1 \%-0.4 \%$ of all malignant tumors. Approximately $50 \%$ of ISCM originates from lung cancer and $20 \%-25 \%$ from breast cancer. ISCM patients are often difficult to treat and have poor prognoses [1] [2] [3]. Among these tumors, intradural 
spinal metastasis damages the spinal cord, cauda equina, or nerve roots depending on the metastatic site, which can result in lower extremity paralysis, perception disturbance, diminished reflexes, back pain, and bladder/rectal disturbance, thereby significantly impairing the patient's quality of life (QOL). Herein, we report our experience with a case of ISCM from breast cancer, in which relatively long survival is achieved with treatment.

\section{Case}

A 67-year-old woman was found in the tumor of the right breast and diagnosed as breast cancer in needle biopsy. She had undergone breast-conserving surgery in May 2010 to treat a mucinous carcinoma of the breast, T2N0M0, $2.5 \mathrm{~cm}$, Grade III, ly (-), v (+), ER (estrogen receptor) (-), PgR (progesterone receptor ) (-) and HER2(human epidermal growth factor receptor type2) (-) (Triple Negative Type). After surgery and 4 cycles of TC (docetaxel + cyclophosphamide ) chemotherapy, the patient was placed on follow-up observation. A routine computed tomography (CT) scan in May 2013 revealed lung metastasis. After administration of 6 cycles of FEC100, complete remission (CR) was achieved for the metastatic lesion in the lung. However, the patient experienced lightheadedness and double vision in December 2013, and magnetic resonance imaging (MRI) revealed multiple cerebellar metastases. After 20-Gy whole-brain irradiation and steroid administration, the symptoms showed amelioration and the patient was given oral anticancer medication (Figure 1). In July 2014, she experienced weakness of the lower extremities and difficulty walking. MRI detected a well-defined intraspinal tumor measuring $13 \times 13 \times 30 \mathrm{~mm}$ at the Th (thoracic) 12 -L (lumbar) 1 level (Figure 2). A vertebral compression fracture of Th12 was also confirmed, and had presumably been caused by bone metastasis. There was a left lower limb advantage of weakness. Posterior tibial muscle by manual muscle test: right $4 / 5$ left $2 / 5$, long and

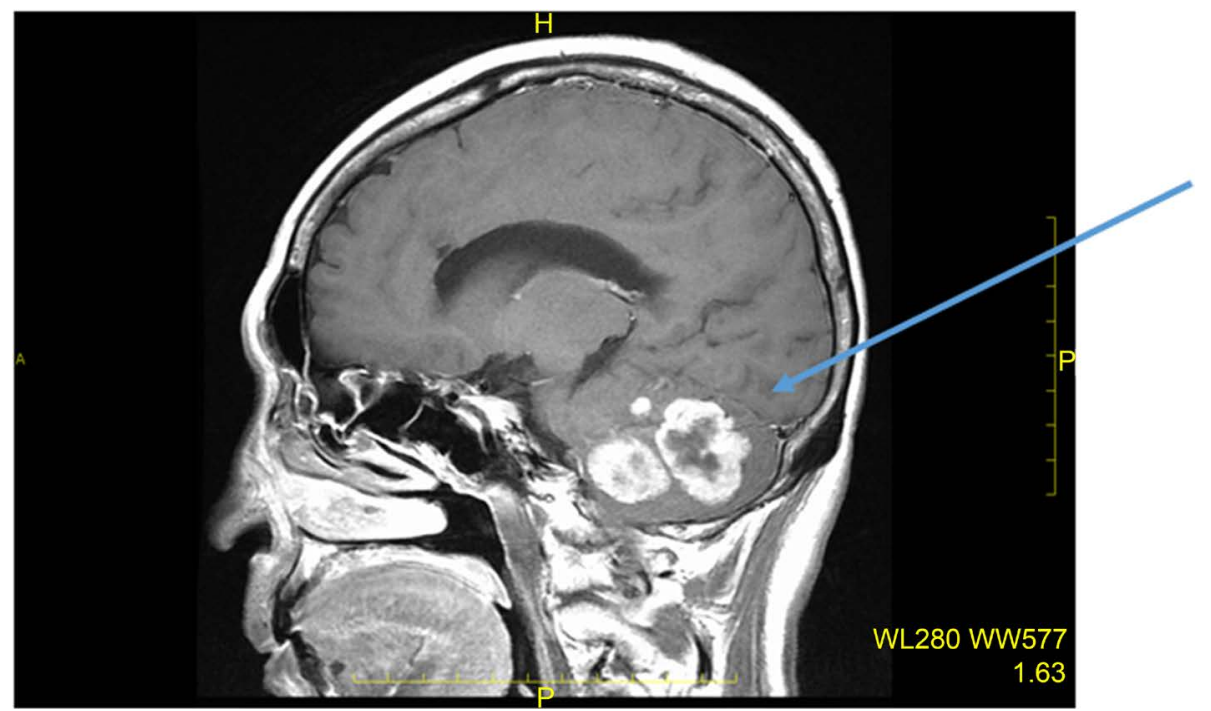

Figure 1. Brain MRI (sagittal plane) Metastatic lesions measuring $30 \mathrm{~mm}$ and $25 \mathrm{~mm}$ can be seen in the right cerebellar hemisphere. 


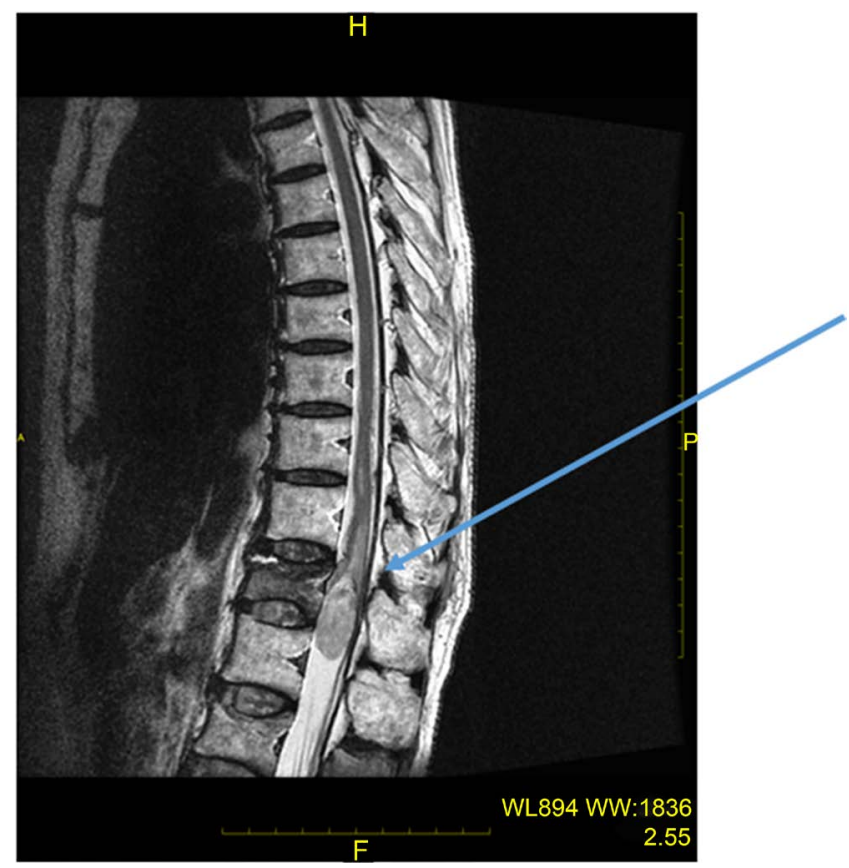

Figure 2. Spain MRI (sagittal plane) a well-defined tumor measuring $30 \times 13 \times 13 \mathrm{~mm}$ can be seen at the Th12-L1 level.

short mother toe extensor muscle: right $4 / 5$ left $2 / 5$, the tibialis anterior muscle: right $4 / 5$ left $2 / 5$. After the delivery of 20 -Gy (gray) irradiation to the spinal cord levels affected by the tumor, recommencement of steroid therapy, and rehabilitation, the patient regained the ability to walk. 3 months after treatment, manual muscle test was slight improved in each muscle. Eight months have passed, to date, since these interventions and she is currently undergoing treatment for metastases to bones, including the spine, but is still capable of walking without difficulty. However, after 12 months she died of systemic metastasis.

\section{Discussion}

Breast cancer metastasis to the central nervous system (CNS) reportedly occurs at a frequency of $6 \%-16 \%$ [2]. In HER2-positive breast cancer particularly, the incidence has increased to $25 \%$ - $34 \%$ due to advances in anti-HER2 therapy [4]. Among these tumors, intradural spinal metastasis damages the spinal cord, cauda equina, or nerve roots depending on the metastatic site, which can result in lower extremity paralysis, perception disturbance, diminished reflexes, back pain, and bladder/rectal disturbance, thereby significantly impairing the patient's quality of life (QOL). Based on the location of the tumor, intradural spinal metastases can be divided into intradural-intramedullary and intradural-extramedullary tumors, corresponding to ISCM and carcinomatous meningitis, respectively.

ISCM is relatively rare, and symptomatic ISCM is reported to comprise $8.5 \%$ of CNS metastases and 1\% - 3\% of spinal cord tumors [1] [2] [3] [4]. At the diagnosis of ISCM, $74 \%$ of patients have systemic metastases and $35 \%$ have CNS metastases, showing that 
other organs are also involved in many such cases [5]. The primary tumors are mostly lung or breast cancer. ISCM patients have poor prognoses compared to those with other forms of CNS metastatic disease, and some reports have indicated that life expectancy after the diagnosis of ISCM is just 3 - 4 months [3]. Of the 2267 patients who underwent breast cancer surgery at our facility (during the 2000 - 2014 period ), 28 (1.2\%) were treated for brain metastases. One symptomatic ISCM patient and 3 with carcinomatous meningitis were treated, all of whom had been pretreated for brain metastases.

MRI is the most effective diagnostic tool for ISCM. [3] [6] On T1-weighted MRI, spinal cord enlargement is shown as an iso- to hypo-intense signal area, which appears relatively well-enhanced with Gd-DTPA contrast agent. On T2-weighted MRI, various signal changes are observed and the tumor and surrounding edema are delineated as hyper-intense signal areas. The present patient had complained of lower extremity weakness during the follow-up observation period after treatment of her brain metastases. MRI was immediately performed, which allowed us to successfully diagnose and treat the condition.

Treatment of ISCM mainly consists of radiation therapy and steroid administration. However, for a solitary brain metastasis with systemic cancer control, the effectiveness of surgical resection has also been reported [7]. ISCM is a form of CNS metastasis. The possibility of surgical treatment has been indicated and there is also a report describing surgical treatment in $34 \%$ of ISCM cases [2]. However cases that are complicated by ISCM and brain metastases in breast cancer, there is a possibility to have a multi-organ metastasis. Therefore, careful consideration is necessary to determine the indications for surgical treatment. In terms of drug therapy, the efficacies of combination chemotherapy with Lapatinib [8] in HER2-positive breast cancer and Bevacizumab [9] in HER2-negative breast cancer have been reported. Whether or not useful to the drug treatment ISCM, it is an issue that should be considered by the stacking of future cases.

\section{Conclusion}

ISCM in the breast cancer is relatively rare. But, it is the clinical condition which it should always place in the mind.

\section{Consent}

Written informed consent was obtained from the patients for publication of this case report and any accompanying images. A copy of the written consent is available for review by the Editor-in-Chief of this journal.

\section{Authors' Contribution}

MK has operated this case and analyzed all data. SY, NT, KI, and SH did the assistant of the operation. All authors read and approved the final manuscript.

\section{Conflict of Interests}

The authors declare that they have no conflict of interests. 


\section{References}

[1] Rostami, R., Safarpour, D., Tavassoli, F.A. and Jabbari, B. (2013) Intramedullary Metastasis in Breast Cancer-A Comprehensive Literature Review. Journal of the Neurological Sciences, 332, 16-20. https://doi.org/10.1016/j.jns.2013.05.032

[2] Kalayci, M., Cağavi, F., Gül, S., Yenidünya, S. and Açikgöz, B. (2004) Intramedullary Spinal Cord Metastases: Diagnosis and Treatment-An Illustrated Review. Acta Neurochirurgica, 146, 1347-1354.

[3] Hashii, H., Mizumoto, M., Kanemoto, A., Harada, H., Asakura, H., Hashimoto, T., Furutani, K., Katagiri, H., Nakasu, Y. and Nishimura, T. (2011) Radiotherapy for Patients with Symptomatic Intramedullary Spinal Cord Metastasis. Journal of Radiation Research, 52, 641-645. https://doi.org/10.1269/jrr.10187

[4] Stemmler, H.J. and Heinemann, V. (2008) Central Nervous System Metastases in HER-2Overexpressing Metastatic Breast Cancer: A Treatment Challenge. Oncologist, 13, 739-750. https://doi.org/10.1634/theoncologist.2008-0052

[5] Potti, A., Abdel-Raheem, M., Levitt, R., Schell, D.A. and Mehdi, S.A. (2001) Intramedullary Spinal Cord Metastases (ISCM) and Non-Small Cell Lung Carcinoma (NSCLC): Clinical Patterns, Diagnosis and Therapeutic Considerations. Lung Cancer, 31, 319-323. https://doi.org/10.1016/S0169-5002(00)00177-X

[6] Kosmas, C., Koumpou, M., Nikolaou, M., Katselis, J., Soukouli, G., Markoutsaki, N., Kostopoulou, V., Gaglia, A., Mylonakis, N., Karabelis, A. and Pectasides, D. (2005) Intramedullary Spinal Cord Metastases in Breast Cancer: Report of Four Cases and Review of the Literature. Journal of Neuro-Oncology, 71, 67-72.

[7] Dam-Hieu, P., Seizeur, R., Mineo, J.F., Metges, J.P., Meriot, P. and Simon, H. (2009) Retrospective Study of 19 Patients with Intramedullary Spinal Cord Metastasis. Clinical Neurology and Neurosurgery, 111, 10-17. https://doi.org/10.1016/j.clineuro.2008.06.019

[8] Cameron, D., Casey, M., Press, M., Lindquist, D., Pienkowski, T., Romieu, C.G., Chan, S., Jagiello-Gruszfeld, A., Kaufman, B., Crown, J., Chan, A., Campone, M., Viens, P., Davidson, N., Gorbounova, V., Raats, J.I., Skarlos, D., Newstat, B., Roychowdhury, D., Paoletti, P., Oliva, C., Rubin, S., Stein, S. and Geyer, C.E. (2008) A Phase III Randomized Comparison of Lapatinib Plus Capecitabine versus Capecitabine Alone in Women with Advanced Breast Cancer That Has Progressed on Trastuzumab: Updated Efficacy and Biomarker Analyses. Breast Cancer Research and Treatment, 112, 533-543. https://doi.org/10.1007/s10549-007-9885-0

[9] Labidi, S.I., Bachelot, T., Ray-Coquard, I., Mosbah, K., Treilleux, I., Fayette, J., Favier, B., Galy, G., Blay, J.Y. and Guastalla, J.P. (2009) Bevacizumab and Paclitaxel for Breast Cancer Patients with Central Nervous System Metastases: A Case Series. Clinical Breast Cancer, 9, 118-121. https://doi.org/10.3816/CBC.2009.n.021 
Submit or recommend next manuscript to SCIRP and we will provide best service for you:

Accepting pre-submission inquiries through Email, Facebook, LinkedIn, Twitter, etc. A wide selection of journals (inclusive of 9 subjects, more than 200 journals)

Providing 24-hour high-quality service

User-friendly online submission system

Fair and swift peer-review system

Efficient typesetting and proofreading procedure

Display of the result of downloads and visits, as well as the number of cited articles

Maximum dissemination of your research work

Submit your manuscript at: http://papersubmission.scirp.org/

Or contact jct@scirp.org 